Article

\title{
A Unique Sugar L-Perosamine (4-Amino-4,6-dideoxy-L-mannose) Is a Compound Building Two O-Chain Polysaccharides in the Lipopolysaccharide of Aeromonas hydrophila Strain JCM 3968, Serogroup O6
}

\author{
Katarzyna Dworaczek ${ }^{1}$, Maria Kurzylewska ${ }^{1}$, Magdalena A. Karaś ${ }^{1}$, Monika Janczarek ${ }^{1}$, \\ Agnieszka Pękala-Safińska ${ }^{2}$ (D) and Anna Turska-Szewczuk 1,*(D) \\ 1 Department of Genetics and Microbiology, Maria Curie-Skłodowska University in Lublin, Akademicka 19, \\ Lublin 20-033, Poland; pakiet.kat@gmail.com (K.D.); mariakurzylewska@wp.pl (M.K.); \\ magdalena.karas@poczta.umcs.lublin.pl (M.A.K.); mon.jan@poczta.umcs.lublin.pl (M.J.) \\ 2 Department of Fish Diseases, National Veterinary Research Institute, Partyzantów 57, Puławy 24-100, \\ Poland; a.pekala@piwet.pulawy.pl \\ * Correspondence: aturska@hektor.umcs.lublin.pl; Tel.: +48-81-537-50-18; Fax: +48-81-537-59-59
}

Received: 9 April 2019; Accepted: 23 April 2019; Published: 28 April 2019

check for updates

\begin{abstract}
Lipopolysaccharide (LPS) is the major glycolipid and virulence factor of Gram-negative bacteria, including Aeromonas spp. The O-specific polysaccharide (O-PS, O-chain, O-antigen), i.e., the surface-exposed part of LPS, which is a hetero- or homopolysaccharide, determines the serospecificity of bacterial strains. Here, chemical analyses, mass spectrometry, and ${ }^{1} \mathrm{H}$ and ${ }^{13} \mathrm{C} N M R$ spectroscopy techniques were employed to study the O-PS of Aeromonas hydrophila strain JCM 3968, serogroup O6. MALDI-TOF mass spectrometry revealed that the LPS of A. hydrophila JCM 3968 has a hexaacylated lipid A with conserved architecture of the backbone and a core oligosaccharide composed of $\mathrm{Hep}_{6} \mathrm{Hex}_{1} \mathrm{HexN}_{1} \mathrm{HexNAc}_{1} \mathrm{Kdo}_{1} \mathrm{P}_{1}$. To liberate the O-antigen, LPS was subjected to mild acid hydrolysis followed by gel-permeation-chromatography and revealed two O-polysaccharides that were found to contain a unique sugar 4-amino-4,6-dideoxy-L-mannose ( $N$-acetyl-L-perosamine, L-Rhap4NAc), which may further determine the specificity of the serogroup. The first O-polysaccharide (O-PS1) was built up of trisaccharide repeating units composed of one $\alpha$-D-GalpNAc and two $\alpha$-L-Rhap4NAc residues, whereas the other one, O-PS2, is an $\alpha 1 \rightarrow 2$ linked homopolymer of L-Rhap4NAc. The following structures of the O-polysaccharides were established:
\end{abstract}

[O-PS1] $\rightarrow 3$ )- $\alpha$-L-Rhap 4 NAc-( $(1 \rightarrow 4)-\alpha$-D-GalpNAc-( $1 \rightarrow 3)-\alpha$-L-Rhap4NAc-( $1 \rightarrow$

[O-PS2] $\rightarrow 2)-\alpha-\mathrm{L}-\mathrm{Rhap} 4 \mathrm{NAc}-(1 \rightarrow$

The present paper is the first work that reveals the occurrence of perosamine in the L-configuration as a component of bacterial O-chain polysaccharides.

Keywords: Aeromonas hydrophila; lipopolysaccharide (LPS); endotoxin; structure elucidation; O-antigen; O-polysaccharide; L-perosamine; L-Rha4NAc; NMR spectroscopy; MALDI-TOF mass spectrometry

\section{Introduction}

Aeromonas bacteria are ubiquitous in aquatic ecosystems, such as seawater, freshwater, and estuarine and coastal waters. They were isolated from chlorinated potable water as well 
as raw and processed food. Aeromonas are either mesophilic motile or psychrophilic non-motile Gram-negative rods [1-3]. They have also been identified as components of the gut microbiome in fish, amphibians, and reptiles. In environmental stress conditions (overcrowding, poor water quality, organic pollution, and hypoxia), these opportunistic bacteria may cause various diseases in poikilothermic animals $[4,5]$. The species Aeromonas hydrophila, Aeromonas salmonicida, Aeromonas caviae, Aeromonas veronii, Aeromonas sobria, and Aeromonas bestiarum have been described as important pathogens in fish. They may cause chronic disease with skin ulceration or acute systemic infection, referred to as motile aeromonad septicemia (MAS), as well as other pathological lesions [5-7]. Water and food may be a source of Aeromonas-origin infections in humans; immunocompromised patients and children are especially vulnerable. Of the 21 species classified on the basis of DNA-DNA hybridization, A. hydrophila, A. caviae, and A. veronii bt. sobria are the most common species known to cause human diseases. They have been recognized as agents of both gastrointestinal diseases and life-threatening extraintestinal infections (wound infections, urinary tract infections and septicemia, occasionally meningitis and peritonitis) $[5,8,9]$.

Extracellularly secreted products of Aeromonas metabolism, including hemolysins, cytotonic and cytotoxic enterotoxins, proteases, lipases, and leucocidins, have been suggested as possible contributory factors in the pathogenesis of these bacteria $[5,10]$. Amongst these, the type II secretion system (secretion of enterotoxin - Act) and the type III secretion system (T3SS) seem to be leading [11]. Moreover, in Gram-negative bacteria, e.g., Aeromonas rods, cell-surface components including outer membrane $(\mathrm{OM})$ proteins, lipopolysaccharide (LPS), S-layer, polar flagella, and pili (type IV and bundle-forming pili) have been implicated as virulence factors [12-16].

LPS, the major glycolipid of the OM, consists of three covalently linked regions: Lipid A (a biological center of endotoxin), the core oligosaccharide (core region), and the O-specific polysaccharide (O-chain, $\mathrm{O}$-antigen), which is a hetero- or homopolysaccharide regarded as the outer cell antigen determining the serospecificity of bacterial strains [17]. High Molecular Weight (HMW) smooth S-type LPS with O-polysaccharide (O-PS) is essential for the adhesion of microorganisms to host tissue and is necessary during infection events, where it protects them from complement-mediated killing and antimicrobial peptides [5]. The structural diversity of the O-chain seems to serve this function, which contributes to the wide variety of antigenic types between species and even strains of Gram-negative bacteria, determining the specificity of each bacterial serotype. On the other hand, serological cross-reactivity sometimes indicates similarities or identities between O-antigens [17,18]. Although it was not clearly evidenced which structural determinants are the most important for virulence, it was found that some O serotypes are more frequently associated with certain infections.

Aeromonas strains are serologically heterogeneous and, according to the first useful NIH scheme (National Institute of Health, Japan) proposed by Sakazaki and Shimada [19], they are classified into 44 serogroups based on O-antigens, which can be further extended to $97 \mathrm{O}$ serogroups, after the inclusion of provisional new serogroups (PG) described by other investigators [20]. As demonstrated in some previous studies, the distribution of the serogroups of Aeromonas strains may be related to geographic localization. Studies have demonstrated that Aeromonas strains belonging to serogroups O11, O16, O18, and O34 (Sakazaki and Shimada scheme) are associated with most cases of bacteremia, implying the O-PS serotypes are relevant in the pathogenesis of some systemic diseases [5]. Geographical differences in the distribution of serogroups of Aeromonas species are associated with outbreaks of septicemia in fish as well. The strains of serogroups O11, O16, O34, and O14 have been related to motile aeromonas septicemia (MAS) incidences in rainbow trout. In turn, strains belonging to O14 have been identified as pathogens for European eels [21]. As shown by Kozińska and Pękala [22], the majority of isolates pathogenic to carp in Polish aquacultures represented serogroups O3, O6, O41, PGO4, and PGO6, whereas serogroups O11, O16, O18, O33, PGO1, and PGO2 dominated among both carp and trout isolates. Until now, the structure of a few Aeromonas O-antigen polysaccharides that tag strains as belonging to serogroups $\mathrm{O} 11, \mathrm{O} 14, \mathrm{O} 34, \mathrm{O} 16$, and $\mathrm{O} 18$ were established [23-28]. Moreover, the chemical composition of the O-antigens of $A$. salmonicida subsp. salmonicida typical strains A449 
and 80204 isolated from salmonids and atypical ones [29,30], A. caviae strain ATCC 15468 [31], A. sobria, and A. bestiarum, have been characterized as well [32-34].

The O-chain polysaccharide in a majority of Aeromonas strains has a heteropolymeric structure with repeating units, which contain mostly 6-deoxyhexoses, hexoses, aminohexoses, and amino 6-deoxyhexoses, frequently decorated with acidic non-carbohydrate groups e.g., $\mathrm{O}$-acetyl, $\mathrm{N}$-acetyl, and 3-hydroxy butyryl [29,34].

In the present study, we have shown the structural characterization of LPS including an O-specific polysaccharide isolated from A. hydrophila strain JCM 3968, which is a reference strain for serogroup O6. We have demonstrated that the O-chain, which is composed of two structurally different O-polysaccharides, contains a unique sugar 4-acetamido-4,6-dideoxy-L-mannose (L-Rha4NAc), which may thus determine the specificity of serogroup O6. To the best of our knowledge, this is the first paper describing the occurrence of a 4-acetamido-4,6-dideoxy-mannose (perosamine) in the absolute configuration $\mathrm{L}$ (L-perosamine) as a component of the bacterial $\mathrm{O}$-specific polysaccharide, $\mathrm{O}$-antigen.

\section{Results}

\subsection{Bacterial Cultivation, Isolation of LPS, and SDS-PAGE Study}

Bacterial cells of Aeromonas hydrophila strain JCM 3968 were extracted with hot aq 45\% phenol [35], and LPS species were harvested from the phenol phase in a yield of $4.8 \%$ of the bacterial cell mass. SDS-PAGE analysis of the LPS followed by silver staining showed a pattern typical for LPS isolated from smooth bacterial cells (Figure 1) with the content of both a slow migrating S-LPS and a fast migrating rough R-LPS glycoforms.

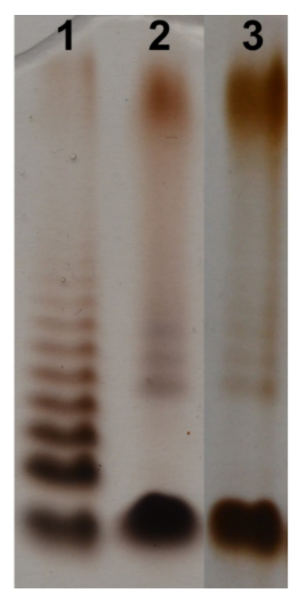

Figure 1. Silver-stained SDS-PAGE of the LPS of A. hydrophila strain JCM 3968, O6 (lane 2, and 3, 2 and $3 \mu \mathrm{g}$, respectively) and Salmonella enterica sv. Typhimurium (Sigma-Aldrich, St. Louis, MO, USA) as reference (lane $1,2 \mu \mathrm{g}$ ).

\subsection{Chemical and Mass Spectrometry Analyses of LPS}

Compositional analysis of the degraded polysaccharide (dgPS) liberated from the phenol-soluble LPS was performed by GLC-MS of alditol acetates. It showed the presence of D-glucose (D-Glc), D-galactose (D-Gal), 2-amino-2-deoxy-D-glucose (D-GlcN), D-glycero-D-manno-heptose (D,D-Hep) and L-glycero-D-manno-heptose (L,D-Hep) in a ratio of 1.0:1.2:1.3:3.0:2.8 as the core oligosaccharide components. The chemical analysis also revealed 6-deoxymannose (Rha), 2-OMe-4-amino-4,6-dideoxyhexose, 4-amino-4,6-dideoxyhexose (identified as Rha4N, see Section 2.3), and GalNAc. These two latter sugars were identified as the main components of the O-PS part (see Section 2.3.). Kdo (3-deoxy-D-manno-2-octulosonic acid)—the only acidic sugar-was found in the LPS after HF (hydrofluoric acid) treatment of the LPS, which suggested its phosphorylation [36,37]. The GLC-MS analysis of fatty acids as methyl esters and O-TMS derivatives revealed that 
3-hydroxytetradecanoic [14:0(3-OH)] and dodecanoic (12:0) acids were the most abundant species. GlcN was identified as the sugar component of the lipid A.

The negative ion matrix-assisted laser desorption/ionization time-of flight (MALDI-TOF) mass spectrum of the A. hydrophila JCM 3968 lipopolysaccharide (Figure 2a) showed the most intensive signals in the $\mathrm{m} / \mathrm{z}$ range 1600-2000. These were Y- and B-type fragments [38] originating from cleavage of the labile ketosidic linkage between lipid A and Kdo of the core oligosaccharide in the LPS molecule as a consequence of in-source fragmentation [28]. The ions at $m / z 1768.18$ and 1796.23 were Y-type fragments of hexaacylated lipid A species. The latter one represented a variant of lipid A, where the diglucosaminyl backbone bisphosphorylated at O- 1 and O-4' is substituted by three, instead of four, 3-hydroxytetradecanoic acids, 14:0(3-OH), one 3-hydroxyisopentadecanoic acid, i15:0(3-OH), and two dodecanoic acids, 12:0. The composition of the ions is shown in Table 1. In turn, the ions at $\mathrm{m} / \mathrm{z} 1977.6$ and 1935.6 were assigned to the core oligosaccharide (B-type) with the following composition: $\mathrm{Hep}_{6} \mathrm{Hex}_{1} \mathrm{HexN}_{2} \mathrm{Kdo}_{a n h} \mathrm{P}$; the mass difference between the ions of 42 amu corresponded to oligosaccharides containing an acetylated and non-acetylated variants of HexN, respectively. In addition, a further B-type ion was observed at $m / z 2555.127$, which was attributed to the core oligosaccharide (OS) with one O-antigen repeating unit attached. The mass difference of $577 \mathrm{amu}$, corresponding to the following composition: $(6 \mathrm{dHexNAc})_{2} \mathrm{HexNAc}-\mathrm{H}_{2} \mathrm{O}$ (calcd monoisotopic mass: 577.24), was in full agreement with the chemical structure of the O-PS1 repeating unit determined by NMR (see Section 2.3.).

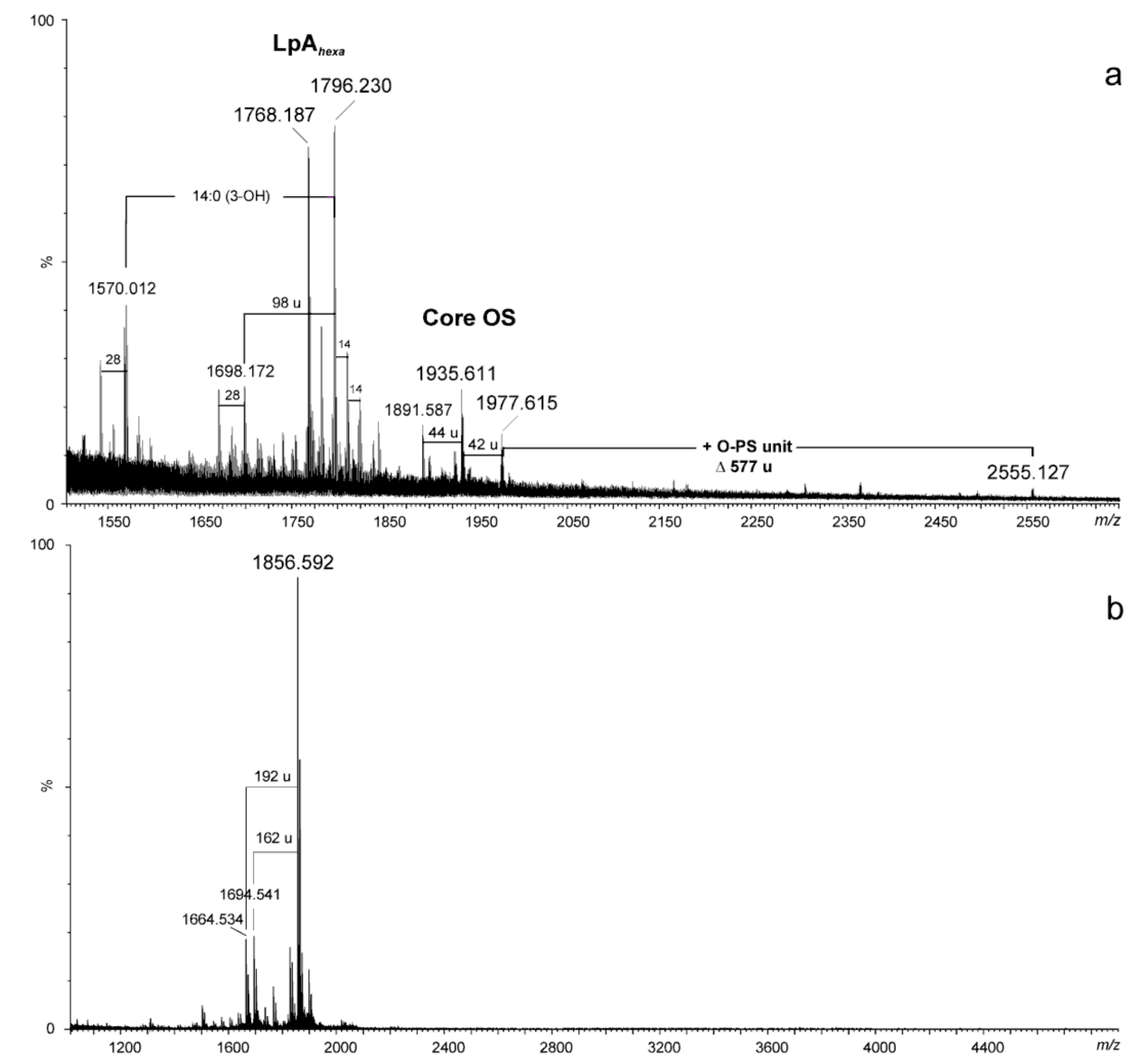

Figure 2. MALDI-TOF mass spectra (negative ion mode) of the LPS (a) and the core oligosaccharide (b) of $A$. hydrophila JCM 3968. The notations indicate: $14 \mathrm{u}$ and $28 \mathrm{u}$ - the differences in $\mathrm{CH}_{2}$ and $\left(\mathrm{CH}_{2}\right)_{2}$ in the fatty acid chains, respectively; $42 \mathrm{u}$ - loss of ketene; $44 \mathrm{u}$ - loss of $\mathrm{CO}_{2} ; 98 \mathrm{u}$ - loss of phosphate plus water; $162 \mathrm{u}$ - loss of hexose, $192 \mathrm{u}$ - loss of heptose; $\mathrm{LpA}_{\text {hexa }}$ - hexaacylated lipid A. 
Table 1. Composition of the main species present in the negative ion MALDI-TOF mass spectra of the LPS (a) and the core oligosaccharide (b) of A. hydrophila JCM 3968.

\begin{tabular}{|c|c|c|c|}
\hline $\begin{array}{l}{[\mathrm{M}-\mathrm{H}]^{-}} \\
\text {Observed }\end{array}$ & $\begin{array}{l}{[\mathrm{M}-\mathrm{H}]^{-}} \\
\text {Calculated }\end{array}$ & $\begin{array}{c}\text { M } \\
\text { Monoisotopic }\end{array}$ & Composition \\
\hline 1570.012 & 1569.946 & 1570.953 & $\mathrm{HexN}_{2} \mathrm{P}_{2}[14: 0(3-\mathrm{OH})]_{2}[i 15: 0(3-\mathrm{OH})](12: 0)_{2}$ \\
\hline 1698.172 & 1698.162 & 1699.169 & $\operatorname{HexN}_{2} \mathrm{P}_{1}[14: 0(3-\mathrm{OH})]_{3}[i 15: 0(3-\mathrm{OH})](12: 0)_{2}$ \\
\hline 1768.187 & 1768.181 & 1769.188 & $\mathrm{HexN}_{2} \mathrm{P}_{2}[14: 0(3-\mathrm{OH})]_{4}(12: 0)_{2}$ \\
\hline 1796.230 & 1796.139 & 1797.146 & $\mathrm{HexN}_{2} \mathrm{P}_{2}[14: 0(3-\mathrm{OH})]_{3}[i 15: 0(3-\mathrm{OH})](12: 0)_{2}$ \\
\hline 1891.587 & 1891.598 & 1892.605 & {$\left[\mathrm{Hep}_{6} \mathrm{Hex}_{1} \mathrm{HexN}_{2} \mathrm{Kdo}_{a n h} \mathrm{P}\right]-\mathrm{COO}$} \\
\hline 1935.611 & 1935.588 & 1936.595 & $\mathrm{Hep}_{6} \mathrm{Hex}_{1} \mathrm{HexN}_{2} \mathrm{Kdo}_{a n h} \mathrm{P}$ \\
\hline 1977.615 & 1977.599 & 1978.606 & $\operatorname{Hep}_{6} \operatorname{Hex}_{1} \mathrm{HexN}_{2} \mathrm{Ac}_{1} \mathrm{Kdo}_{a n h} \mathrm{P}$ \\
\hline 2555.127 & 2554.846 & 2555.853 & {$\left[6 \mathrm{dHexNAc}_{2} \mathrm{HexN}_{3} \mathrm{Ac}_{2} \mathrm{Hep}_{6} \mathrm{Hex}_{1} \mathrm{Kdo}_{a n h} \mathrm{P}\right]-\mathrm{H}_{2} \mathrm{O}$} \\
\hline 1664.534 & 1664.542 & 1665.550 & $\mathrm{Hep}_{5} \mathrm{Hex}_{2} \mathrm{HexN}_{1} \mathrm{Kdo}_{a n h}$ \\
\hline 1694.541 & 1694.553 & 1695.560 & $\mathrm{Hep}_{6} \mathrm{Hex}_{1} \mathrm{HexN}_{1} \mathrm{Kdo}_{a n h}$ \\
\hline 1856.592 & 1856.605 & 1857.613 & $\mathrm{Hep}_{6} \mathrm{Hex}_{2} \mathrm{HexN}_{1} \mathrm{Kdo}_{a n h}$ \\
\hline
\end{tabular}

The negative ion mass spectrum recorded for the core oligosaccharide, which was liberated from LPS after mild acid hydrolysis and separation by gel-permeation-chromatography, GPC, showed the major ion at $\mathrm{m} / \mathrm{z} 1856.59$, corresponding to the core decasaccharide with the composition $\mathrm{Hep}_{6} \mathrm{Hex}_{2} \mathrm{HexN}_{1} \mathrm{Kdo}_{\text {anh }}$ (calcd monoisotopic mass, = $1857.613 \mathrm{amu}$, calcd mass of deprotonated molecule $=1856.606 \mathrm{amu})($ Figure 2b, Table 1). The methylation analysis of the $\mathrm{N}$-acetylated oligosaccharide fraction, followed by full acid hydrolysis and GLC-MS of partially methylated monosaccharides as acetylated alditols-1- $d$, revealed terminal Gal, terminal GlcN, 6-substituted Glc, terminal D,D-Hep, terminal L,D-Hep, and 4,6-disubstituted D,D-Hep, 7-substituted, 2-substituted, and 3,4,6-trisubstituted L,D-Hep. A similar composition and glycosylation pattern of the monosaccharides as well as the measured molecular mass of the core oligosaccharide was shown for the LPS core OS of A. hydrophila AH-901, i.e., a rough mutant strain derived from A. hydrophila AH-3 [36].

In turn, the identification of the 3-substituted GalNAc detected among permethylated alditol acetates of the dgPS and the composition of the core oligosaccharide indicating the presence of $\mathrm{N}$-acetylated hexosamine rather than a hexose residue (established based on the mass spectrometry data of intact LPS) might suggest that the O-antigen in the LPS of A. hydrophila strain JCM 3968 is linked to the GalNAc as in A. salmonicida subsp. salmonicida A450 LPS [39].

\subsection{Structural Studies of O-polysaccharide (O-PS)}

The O-PS was released from phenol-soluble LPS by mild-acid degradation followed by gel-permeation-chromatography (GPC) on Sephadex G-50 fine to give a high-molecular-mass O-polysaccharide with the yield of $31 \%$ of the LPS mass. GLC-MS sugar analysis of alditol acetates obtained after full acid hydrolysis of the O-PS showed the presence of 4-amino-4,6-dideoxyhexose identified as 4-amino-4,6-dideoxymannose (Rha4N) by comparison with an authentic sample from the polysaccharide of Citrobacter gillenii O9a,9b (strain PCM 1537) [40] and galactosamine $(\mathrm{GalN})$ in a peak area ratio $\sim$ 4.2:1. Among amino sugar derivatives, a small amount of 2-O-methyl-4-amino-4,6-dideoxyhexitol acetate (Rha4N2Me) was found as well. Other compounds detected in the GLC chromatogram of the A. hydrophila 3968 O-PS, i.e., GlcN and two heptose isomers (D,D-Hep and L,D-Hep), represented the core oligosaccharide sugars.

Determination of the absolute configurations of the monosaccharides by GLC of the acetylated (S)- and (SR)-2-octyl glycosides [41] showed that Rha4N had the L configuration and GalN had the D configuration. A sample from the polysaccharide of Citrobacter gillenii O9a,9b [40] was used as a reference standard of $\mathrm{D}-\mathrm{Rh} 4 \mathrm{~N}$. The $\mathrm{L}$ configuration of Rha4N was also confirmed by the analysis of glycosylation effects in the ${ }^{13} \mathrm{C}$ NMR spectrum of the O-PS (see below). 
The methylation analysis of the O-PS by GLC-MS of partially methylated alditol acetates resulted in identification of 4,6-dideoxy-3-O-methyl-4-( $\mathrm{N}$-methyl)acetamidohexose (derived from 2-substituted Rha4N), 4,6-dideoxy-2-O-methyl-4-( $\mathrm{N}$-methyl)acetamidohexose (derived from 3-substituted Rha4N), and 2-deoxy-3,6-di-O-methyl-2-( $\mathrm{N}$-methyl)acetamidohexose (derived from 4-substituted GalN). Additionally, the $\mathrm{CD}_{3}$-methylation indicated a small amount of 4,6-dideoxy-2-O-methyl-4-( $\left.\mathrm{N}-\mathrm{CD}_{3}\right)$-acetamidohexose (derived from 3-substituted 2-OMe Rha4N). The EI mass spectrum of 4,6-dideoxy-2-O-methyl-4-( $\mathrm{N}$-methyl)acetamidomannose was characterized by the presence of intense ion peaks at $\mathrm{m} / \mathrm{z} 118$ (C-1 $\div \mathrm{C} 2$ fragment), 275 (C-1 $\div \mathrm{C} 4$ fragment), and 172 (C-4 $\div$ C6 fragment), and allowed distinguishing this derivative from 4,6-dideoxy-3-O-methyl-4-( $\mathrm{N}$-methyl)acetamidomannose, whose $E I$ mass spectrum contained ions at $\mathrm{m} / \mathrm{z} 190,275$, and 172 characteristic of the $\mathrm{C}-1 \div \mathrm{C} 3, \mathrm{C}-1 \div \mathrm{C} 4$, and $\mathrm{C}-4 \div \mathrm{C} 6$ primary fragments, respectively.

The low-field region of the ${ }^{1} \mathrm{H}$ NMR spectrum of the O-polysaccharide (Figure 3) contained four major signals for anomeric protons at $\delta 5.17,5.16,5.04$, and 5.0. The high-field region of the spectrum included signals for $\mathrm{N}$-acetyl groups at $\delta 2.05-2.06, \mathrm{CH}_{3}-\mathrm{C}$ groups of 6-deoxy sugars in the range of $\delta 1.19-1.23$, and a less intense signal of an $O$-methyl group at $\delta 3.5$; some of the signals overlapped. The ${ }^{1} \mathrm{H}$ and ${ }^{13} \mathrm{C}$ resonances of the O-PS of $A$. hydrophila JCM 3968, O6 were assigned using 2D homonuclear ${ }^{1} \mathrm{H},{ }_{1}^{1} \mathrm{H}$ DQF-COSY, TOCSY, NOESY, heteronuclear ${ }^{1} \mathrm{H},{ }^{13} \mathrm{C}$ HSQC, and $\mathrm{HMBC}$ experiments. The ${ }^{1} \mathrm{H}$ and ${ }^{13} \mathrm{C}$ NMR data are collected in Table 2.

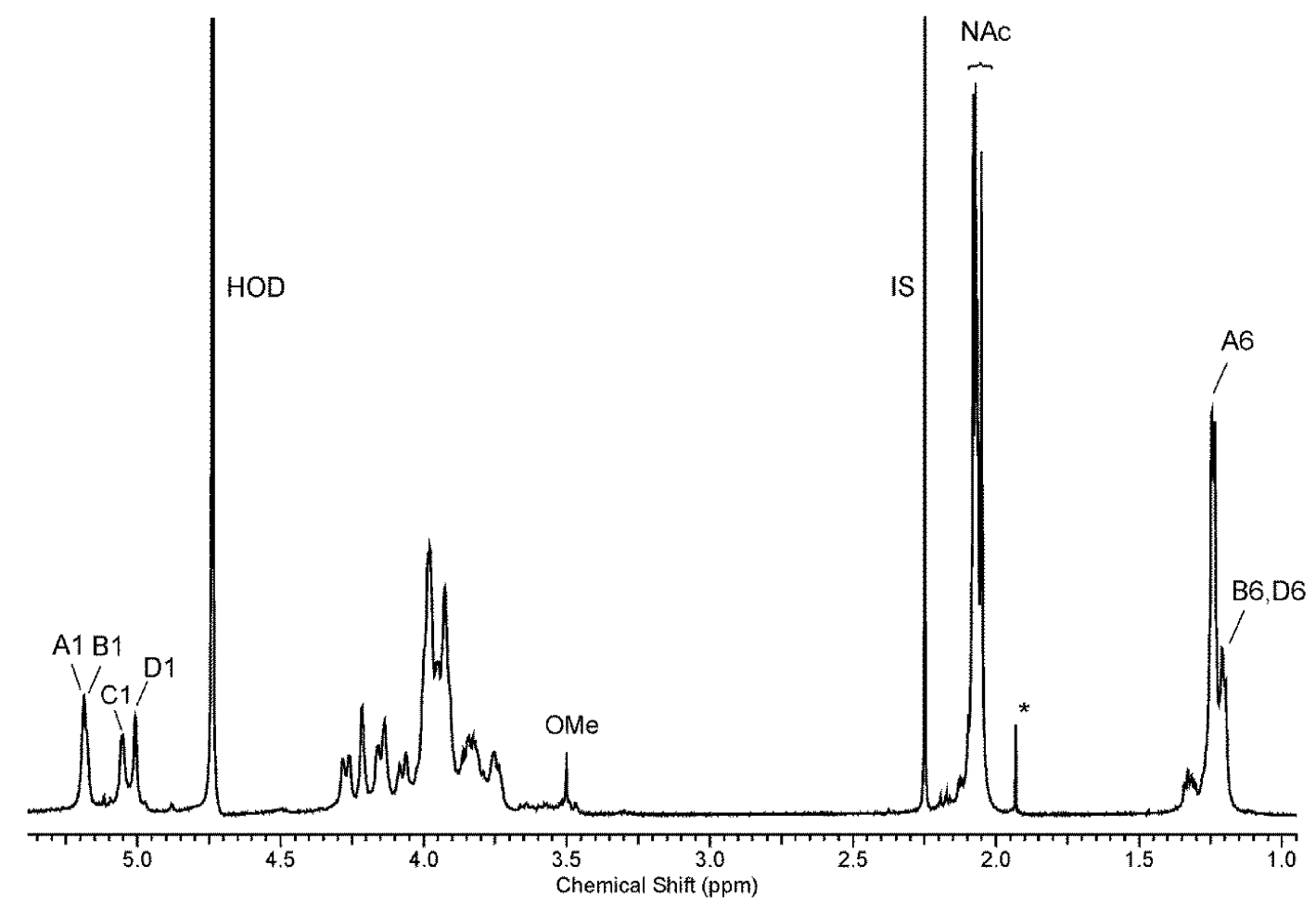

Figure 3. ${ }^{1} \mathrm{H}$ NMR spectrum of the O-PS of $A$. hydrophila JCM 3968, serotype O6. The spectrum was recorded in $\mathrm{D}_{2} \mathrm{O}$ at $32{ }^{\circ} \mathrm{C}$ at $500 \mathrm{MHz}$. Capital letters and Arabic numerals refer to atoms in the sugar residues denoted as shown in Table 2. NAc - N-acetyl groups, IS - acetone as an internal standard $\left(\delta_{\mathrm{H}}\right.$ 2.225), OMe - O-methyl group, asterisk - free acetic acid. 
Table 2. ${ }^{1} \mathrm{H}(500 \mathrm{MHz})$ and ${ }^{13} \mathrm{C}$ NMR $(125 \mathrm{MHz})$ data $(\delta, \mathrm{ppm})$ for the O-PS of $A$. hydrophila strain JCM 3968.

\begin{tabular}{|c|c|c|c|c|c|c|c|}
\hline \multirow{3}{*}{ Sugar Residue } & & \multicolumn{6}{|c|}{ Chemical Shifts $(\delta$, ppm) } \\
\hline & & H-1 & H-2 & H-3 & H-4 & H-5 & H-6 \\
\hline & & C-1 & $\mathrm{C}-2$ & $\mathrm{C}-3$ & C-4 & $C-5$ & C-6 \\
\hline \multirow{2}{*}{$\rightarrow 3)-\alpha-\mathrm{L}-\mathrm{Rh} a p 4 \mathrm{NAc}-(1 \rightarrow$} & \multirow{2}{*}{$\mathbf{A}$} & 5.17 & 4.20 & 3.97 & 3.97 & 3.92 & 1.23 \\
\hline & & 103.0 & 70.3 & $\underline{78.0}$ & 52.5 & 69.4 & 18.0 \\
\hline \multirow{2}{*}{$\rightarrow 2)-\alpha-L-R h a p 4$ NAc- $(1 \rightarrow$} & \multirow{2}{*}{ B } & 5.16 & 4.15 & $\overline{4.05}$ & 3.91 & 3.84 & 1.19 \\
\hline & & 101.7 & 78.2 & 69.2 & 54.3 & 69.6 & 18.0 \\
\hline \multirow{2}{*}{$\rightarrow 4)-\alpha-\mathrm{D}-G a l p N A c-(1 \rightarrow$} & \multirow{2}{*}{$\mathrm{C}$} & 5.04 & $\overline{4.26}$ & 3.97 & 4.12 & 3.90 & $3.74,3.81$ \\
\hline & & 95.0 & 50.9 & 69.2 & $\underline{77.2}$ & 72.7 & 62.2 \\
\hline \multirow{2}{*}{$\rightarrow 3)-\alpha-L-R h a p 4 N A c-(1 \rightarrow$} & \multirow{2}{*}{ D } & 5.00 & 3.91 & 3.94 & $\overline{3.98}$ & 3.92 & 1.23 \\
\hline & & 103.0 & 67.0 & $\underline{74.3}$ & 52.3 & 69.4 & 18.0 \\
\hline
\end{tabular}

Chemical shifts for NAc are $\delta_{\mathrm{H}} 2.05-2.06$ and $\delta_{\mathrm{C}} 23.3-23.4 / 175.6-176.0$.

The ${ }^{1} \mathrm{H},{ }^{13} \mathrm{C}$ HSQC spectrum (Figure 4) showed four intense correlation signals at $\delta 3.91 / 54.3$, $3.97 / 52.5,3.98 / 52.3$, and $4.26 / 50.9$ of the proton at the nitrogen-bearing carbon to the corresponding carbon and indicated that the O-PS is built up of $\mathrm{N}$-acetamido sugars.

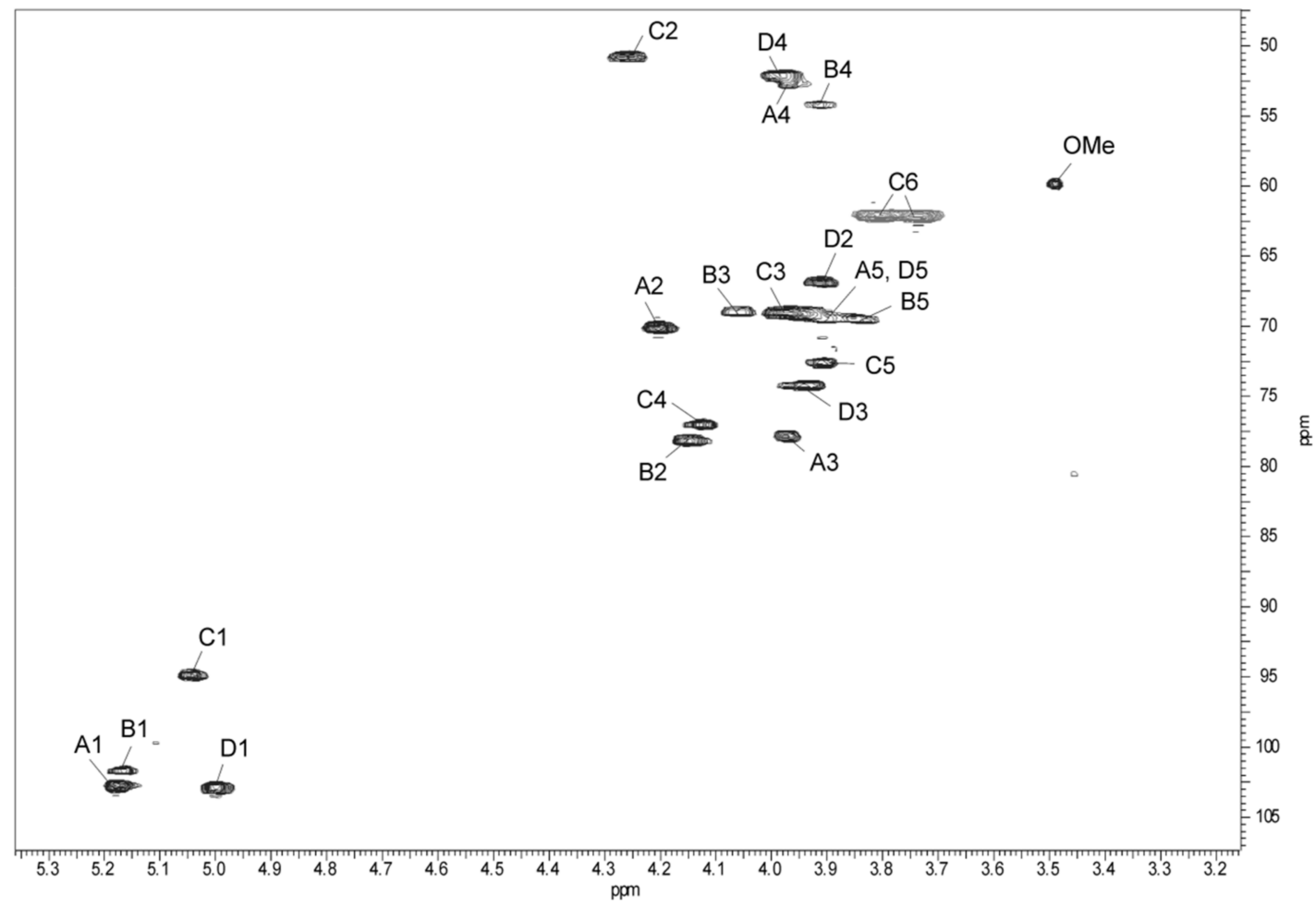

Figure 4. Part of a ${ }^{1} \mathrm{H}^{13} \mathrm{C}$ HSQC spectrum $(500 \times 125 \mathrm{MHz})$ of the O-PS of A. hydrophila JCM 3968, serotype O6. The spectrum was recorded at $32{ }^{\circ} \mathrm{C}$ in $\mathrm{D}_{2} \mathrm{O}$ as a solvent. Capital letters and Arabic numerals refer to atoms in sugar residues denoted as shown in Table 2. OMe - O-methyl group of Rha4N2Me, chemical shifts for $O M e$ are $\delta_{\mathrm{H}} 3.5$ and $\delta_{\mathrm{C}} 60.0$.

The ${ }^{1} \mathrm{H}_{1}^{1} \mathrm{H}$ TOCSY, and DQF-COSY spectra revealed four major spin systems for monosaccharide residues, which were labelled $\mathbf{A}-\mathbf{D}$ in the order of the decreasing chemical shifts of their anomeric protons. The A, B, and D spin systems (H-1/C-1 cross-peaks at $\delta 5.17 / 103.0,5.16 / 101.7$, and 5.0/103.0, respectively) were typical of manno-pyranose, as indicated by low vicinal coupling constants ${ }^{3} J_{1,2}$ $(\sim 2 \mathrm{~Hz})$, and high ${ }^{3} J_{3,4}(8.5 \mathrm{~Hz}),{ }^{3} J_{4,5}(9 \mathrm{~Hz})$, and ${ }^{3} J_{5,6}(6 \mathrm{~Hz})$ values. They were assigned to Rha4NAc 
residues based on high-field positions of their H-6 and C-6 resonances and taking into account nitrogen-bearing carbons.

In the TOCSY spectrum, starting from the H-2 proton signal, cross-peaks with $\mathrm{H}-2-\mathrm{H}-6$ for Rha4NAc B as well as Rha4NAc A and Rha4NAc D were visible; however, some signals of the two latter residues overlapped. The ${ }^{1} \mathrm{H},{ }^{1} \mathrm{H}$ COSY spectrum allowed unambiguous differentiation between protons within the spin system $\mathbf{B}$ and only partly resolved the cross-peaks for the Rha4NAc $\mathbf{A}$ and Rha4NAc D. The difficulties in the assignment of the H-3, H-4, and H-5 of Rha4NAc A and D were overcome in the ${ }^{1} \mathrm{H},{ }^{13} \mathrm{C}$ HMBC and ${ }^{1} \mathrm{H},{ }^{13} \mathrm{C}$ HSQC experiments.

The ${ }^{13} \mathrm{C}$ NMR resonances of Rha4NAc A were assigned by the long-range $\mathrm{H}-6 / \mathrm{C}-4$ and $\mathrm{H}-6 / \mathrm{C}-5$ correlations at $\delta 1.23 / 52.5$ and 1.23/69.4, and then the $\mathrm{C}-4 / \mathrm{H}-3$ correlation at $\delta 52.5 / 3.97$ in the ${ }^{1} \mathrm{H}^{13} \mathrm{C}$ $\mathrm{HMBC}$ spectrum. In the ${ }^{1} \mathrm{H},{ }^{13} \mathrm{C}$ HSQC spectrum, the cross-peak of the proton at the nitrogen-bearing carbon to the corresponding carbon at $\delta 3.97 / 52.5$ was assigned to the H-4/C-4 correlation of Rha4NAc A. Similar long-range H-6/C-4 and H-6/C-5 correlations were searched during identification of $\mathrm{H}-4$ and $\mathrm{H}-5$ proton signals of Rha4NAc D. For the latter residue, correlations of the anomeric proton of Rha4NAc D with carbons C-2, C-3, and C-5 were found in the ${ }^{1} \mathrm{H}^{13} \mathrm{C}$ HMBC spectrum, and then the proton resonances were assigned from the ${ }^{1} \mathrm{H},{ }^{13} \mathrm{C}$ HSQC spectrum. The chemical shifts of the $\mathrm{C}-3$ signals of Rha4NAc $\mathbf{A}$ and $\mathbf{D}$ were identified after consideration of the methylation analysis data and the glycosylation effects on the ${ }^{13} \mathrm{C}$ NMR resonances. The fifth spin system at $\delta_{\mathrm{H} / \mathrm{C}} 5.11 / 100.0$, with much less intense correlation signals and not completely resolved resonances, was assigned to the Rha4N2Me residue.

In the TOCSY spectrum, correlations for the galacto configuration of the spin system $\mathbf{C}$ were visible between $\mathrm{H}-1$ and $\mathrm{H}-2, \mathrm{H}-3, \mathrm{H}-4$, and other proton signals were assigned by connectivities observed in the NOESY (H-3/H-5; H4/H-6) and COSY (H-6/H-5) spectra. In the ${ }^{1} \mathrm{H}_{1}{ }^{13} \mathrm{C}$ HSQC spectrum, the correlations of $\mathrm{H}-2$ at $\delta 4.26$ with a nitrogen-bearing carbon at $\delta 50.9$ and $\mathrm{H}-6$ protons with C-6 at $\delta 3.74 ; 3.81 / 62.2$ completed identification of the GalNAc residue $\mathbf{C}$.

The relatively small ${ }^{3} J_{1,2}$ coupling constant value of $<4 \mathrm{~Hz}$ indicated that GalNAc is $\alpha$-linked. This conclusion was confirmed by relatively high-filed position of the C- 5 signal at $\delta 72.7$, compared with $\delta 71.7$ and $\delta 76.4$ for $\alpha$-GalNAc and $\beta$-GalNAc, respectively [42]. The $\alpha$-configuration of all Rha4NAc residues was inferred by a relatively high-field position of the C-5 signals at $\delta 69.4-69.6$ for the residues in the O-polysaccharides, compared with $\delta 72.4$ for $\beta$-Rha4NAc [42,43]. The $\alpha$-configuration of monosaccharides was confirmed by intraresidue H-1/H-2 cross-peaks for $\alpha$-GalNAc and $\alpha$-Rha4NAc residues in the NOESY spectrum (Figure 5).

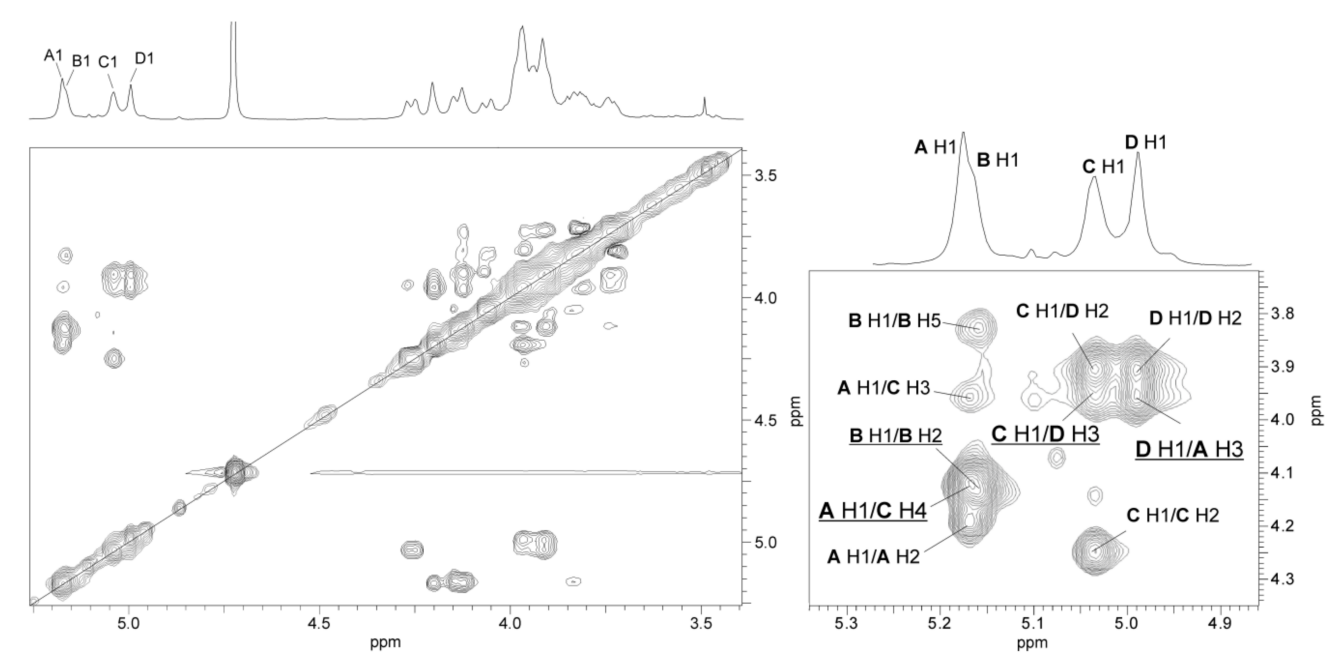

Figure 5. Parts of ${ }^{1} \mathrm{H},{ }_{1}^{1} \mathrm{H}$ NOESY and ${ }^{1} \mathrm{H}$ NMR (insert) spectra of the O-PS of A. hydrophila JCM 3968 , serotype O6. The map shows NOE contacts between anomeric protons and protons at the glycosidic linkages (underlined). Some other $\mathrm{H} / \mathrm{H}$ correlations are depicted as well. Capital letters and Arabic numerals refer to atoms in the sugars denoted as shown in Table 2. 
The ${ }^{1} \mathrm{H},{ }^{13} \mathrm{C}$ HMBC spectrum showed correlations between $\mathrm{H}-2$ of GalNAc and $\mathrm{H}-4$ of all the Rha4NAc residues and carbonyl group signals in the range of $\delta_{C} 175.6-176.0$ and between the latter and methyl proton signals at $\delta_{\mathrm{H}} 2.05-2.06$. This confirmed that all residues building the O-PS are $N$-acetylated.

The relatively low-field positions of the signals for C-3 of Rha4NAc A and D, C-2 of Rha4NAc B, and C-4 of GalNAc $C$ at $\delta 78.0,74.3,78.2$ and 77.2, respectively, compared with their positions in the spectra of the corresponding non-substituted monosaccharides [42-44], were in agreement with the methylation analysis data and demonstrated the glycosylation pattern of the sugar residues.

The NOESY spectrum (Figure 5) showed interresidue cross-peaks between residues $\mathbf{A} \rightarrow \mathbf{C}, \mathbf{C} \rightarrow \mathbf{D}$, and $\mathbf{D} \rightarrow \mathbf{A}$. The correlations between the following anomeric protons and protons at the linkage carbons: Rhap4NAc A H-1/GalpNAc C H-4 at $\delta$ 5.17/4.12; GalpNAc C H-1/Rhap4NAc D H-3 at $\delta$ 5.04/3.94; and Rhap4NAc D H-1/Rhap4NAc A H-3 at $\delta$ 5.0/3.97 indicated that the polysaccharide O-PS1 is a heteropolymer with a trisaccharide repeating unit (Figure 5, Table 2). In turn, in the NOESY spectrum, intraresidue $\mathrm{H}-1 / \mathrm{H}-2$ and interresidue $\mathrm{H}-1 / \mathrm{H}-5$ correlations at $\delta 5.16 / 4.15$ and $\delta 5.16 / 3.84$, respectively, typical of $\alpha-(1 \rightarrow 2)$-linked sugars with the manno configuration, indicated that the Rha4NAc B residues constitute the other structurally different O-polysaccharide (O-PS2).

The ${ }^{1} \mathrm{H},{ }^{13} \mathrm{C}$ HMBC spectrum (Figure 6) displayed the following inter-glycosidic cross-peaks: A H-1/C C-4 at $\delta$ 5.17/77.2; C H-1/D H-3 at $\delta 5.04 / 74.3$; and D H-1/A H-3 at $\delta 5.0 / 78.0$ and revealed the sequence of sugars in the polysaccharide O-PS1.
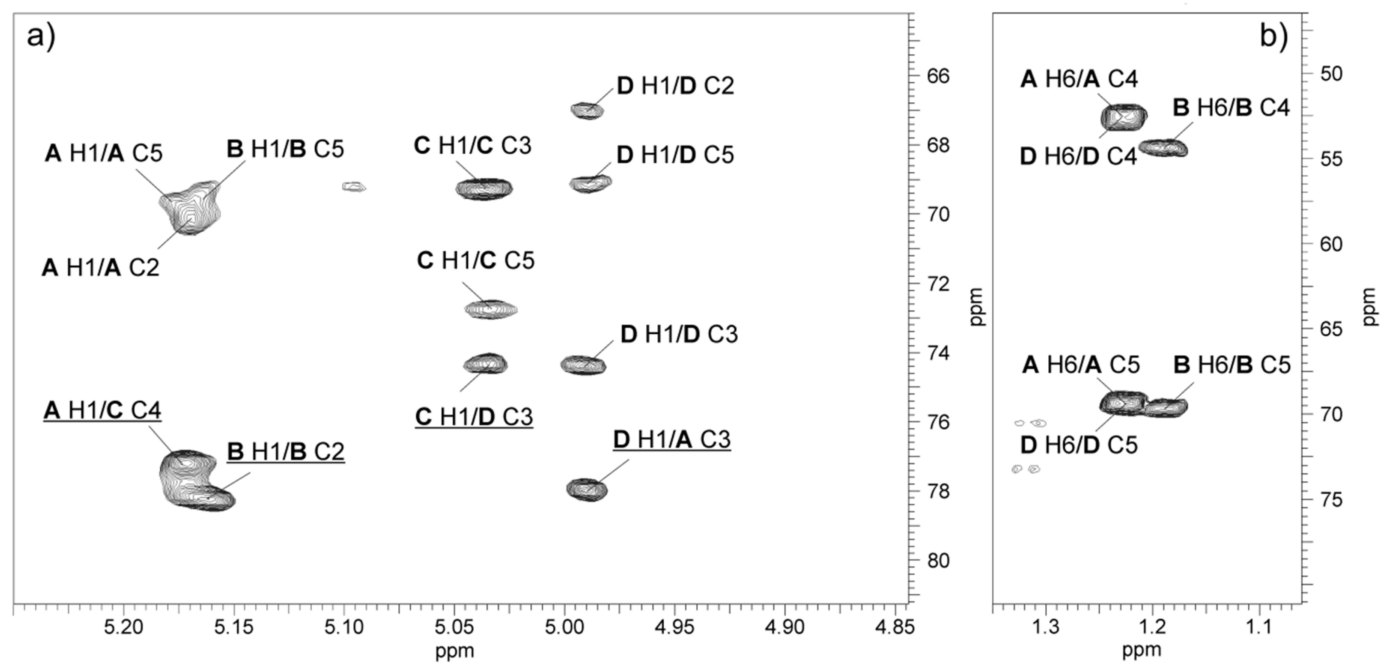

Figure 6. Regions of the ${ }^{1} \mathrm{H}_{,}^{13} \mathrm{C}$ HMBC spectrum of the O-PS of A. hydrophila JCM 3968, serotype O6. The maps show heteronuclear correlations for: (a) Anomeric protons, and (b) H-6 protons. Interresidue correlations between anomeric protons and carbons at the glycosidic linkages are underlined. Some other correlations $\mathrm{H} / \mathrm{C}$ are depicted as well. Capital letters and Arabic numerals refer to protons or carbons in the sugar residues denoted as shown in Table 2.

The analysis of the glycosylation effects on the ${ }^{13} \mathrm{C}$ NMR chemical shifts confirmed the absolute configuration of Rha4NAc residues in the A. hydrophila JCM 3968 O-PS. The relatively small $\alpha$-glycosylation effects of $3.0 \mathrm{ppm}$ on C-1 of $\alpha$-D-GalpNAc and of $3.3 \mathrm{ppm}$ on C-3 of Rha4NAc indicated different absolute configurations of the constituents in the disaccharide fragment $\alpha$-D-GalpNAc-(1 $\rightarrow 3)-\alpha$-L-Rhap4NAc D [45]. On the contrary, the relatively large $\alpha$-effects of $>8$ ppm on C-1 of L-Rha4NAc D and $\sim 7$ ppm on C-3 in the $\alpha$-L-Rhap4NAc- $(1 \rightarrow 3)-\alpha-\mathrm{L}-\mathrm{Rh} a p 4 \mathrm{NAc}$ disaccharide fragment showed that the constituent monosaccharides have the same absolute configuration, i.e., Rha4NAc A has the L configuration (in the case of their different configurations, the effect on C- 1 would be $<5 \mathrm{ppm}$ ) [45]. 
In the disaccharide fragment $\alpha$-D-GalpNAc-( $1 \rightarrow 3)-\alpha$-L-Rhap $4 N A c D$, the relatively large negative $\beta$-effect of $>4$ ppm on C-2 of Rha4NAc caused by its glycosylation at O-3 with $\alpha$-D-GalpNAc indicated that the linked monosaccharides have different absolute configurations, as the effect on $\mathrm{C}-2$ in the case of the same configurations would be $<1 \mathrm{ppm}$. The latter variant, i.e. a relatively small negative $\beta$-effect on C-2 of Rha4NAc caused by glycosylation at O-3, was observed in the $\alpha$-L-Rhap 4 NAc- $(1 \rightarrow 3)-\alpha$-L-Rhap 4 NAc disaccharide fragment, where the linked monosaccharides have the same absolute configuration $\mathrm{L}$ [45].

In conclusion, the O-antigen of A. hydrophila JCM 3968, serogroup O6 consists of two structurally different O-polysaccharides. One of them (O-PS1) is a heteropolymer built up of trisaccharide repeating units composed of one $\alpha$-D-GalpNAc and two $\alpha-(1 \rightarrow 3)$-linked L-Rhap4NAc residues. The other polysaccharide, O-PS2, is an $\alpha-(1 \rightarrow 2)$-linked homopolymer of L-Rha4NAc.

Based on the composition and methylation analyses as well as NMR data, the following structures of the O-polysaccharides were established:

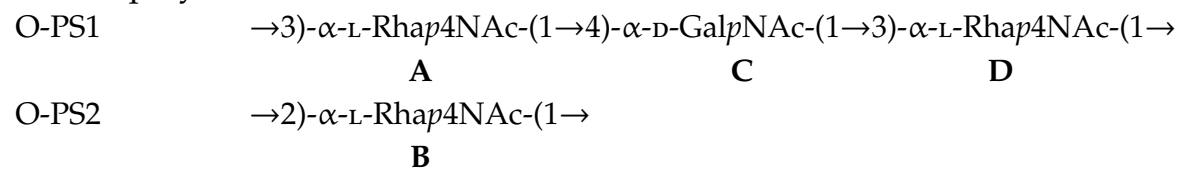

The structure of the O-antigen is unique among O-polysaccharides of Aeromonas bacteria as well as other bacterial O-polysaccharides. To the best of our knowledge, this is the first work that shows the occurrence of L-perosamine as a component of bacterial O-polysaccharides.

\section{Discussion}

Lipopolysaccharide (LPS, endotoxin), which is an important virulence factor of Gram-negative bacteria, belongs to molecules classified as PAMP (Pathogen Associated Molecular Patterns) being a powerful activator of the innate immune response during host invasion. The S-LPS species of smooth bacteria are composed of three domains: lipid A, a core oligosaccharide, and an O-specific polysaccharide. The lipid A moiety critically affects the biological activity of endotoxin by mediating the interaction of LPS with pattern recognition receptors, such as toll-like receptor 4 (TLR-4) on monocytes and macrophages, which eventually results in production of proinflammatory cytokines in response to the pathogen invasion [17,46-48]. In turn, the variable chemical structure of the O-polysaccharide portion determines the immunospecificity of individual bacterial strains and has become the basis for classification thereof to appropriate O serogroups. Serological typing has been used in epidemiological studies to define the routes of transmission or relationships with pathogenicity [49]. It is known that the specific $\mathrm{O}$ serogroups can be associated with certain clinical syndromes. Therefore, serological typing methods are valuable to relate characteristic serogroups, within many genera of Gram-negative bacteria e.g., Escherichia coli, Salmonella, Proteus, Citrobacter, and Aeromomas, with virulence and several diseases.

In this work, we established the structure of the O-antigen of A. hydrophila strain JCM 3968 (serogroup $\mathrm{O} 6$ reference strain) and found that it consisted of two different O-polysaccharides. The studied O-chain is unique among O-polysaccharides of Aeromonas bacteria as well as other bacterial O-polysaccharides (Bacterial Carbohydrate Structure Database: http://glyco.ac.ru/bcsdb). Moreover, another peculiar characteristic of the O-PS of $A$. hydrophila JCM3968, O6 that is worth emphasizing is the presence of 4-amino-4,6-dideoxymannose (Rha4N, perosamine), i.e., quite an unusual amino sugar, in the $\mathrm{L}$-configuration. This is the first work that shows the occurrence of $\mathrm{L}$-perosamine as a component of bacterial O-polysaccharides, whereas Rha4N in the D-configuration has been found as a sugar building some bacterial O-antigens.

As reported here for the O-PS of A. hydrophila JCM 3978 serogroup O6, two structurally different polysaccharides, but containing D-perosamine, were identified in the O-polysaccharides of e.g., Citrobacter gillenii O9 (strain PCM 1537) [40], Citrobacter youngae O9 (strain PCM 1538) [43], and Brucella melitensis (strain 16M) [50,51]. One O-polysaccharide has been found to contain disaccharide, tetrasaccharide, or pentasaccharide repeating units composed of $\alpha 1 \rightarrow 2$ and $\alpha 1 \rightarrow 3$-linked 
residues of $\mathrm{N}$-acetyl-D-perosamine or $\mathrm{N}$-formyl-D-perosamine, as reported for the O-PS of $\mathrm{C}$. youngae $\mathrm{O} 9, \mathrm{C}$. gillenii $\mathrm{O} 9$, and B. melitensis, respectively. In turn, the other O-polysaccharide is an $\alpha 1 \rightarrow 2$-linked homopolymer of 2-substituted D-perosamine residues $\mathrm{N}$-acylated with various groups. Based on matrix-assisted laser-desorption/ionization mass spectrometry data, it was suggested that the O-chain elongation in the biosynthesis of both O-PS proceeds via sequential transfers of single sugar units to the nonreducing end of the growing polysaccharide chain. This model of biosynthesis requires the contribution of several distinct transferases for the same monosaccharide [52].

D-Rha4N was also detected as a sugar constituent of branched or linear bacterial O-antigens. The O-polysaccharides of Brucella abortus strain 1119-3 [53] and Yersinia enterocolitica O9 [54] are $\alpha$-(1 $\rightarrow 2)$-linked homopolymers of $N$-formyl-D-perosamine. In turn, homopolysaccharides of 4-amino-4,6-dideoxy-D-mannose decorated with (S)-2,4-dihydroxybutyryl or $\mathrm{N}$-acetyl groups were found in the O-chains of Vibrio cholerae O1 and marine V. cholerae strain 487-85 (bio-serogroup Hakata), respectively $[55,56]$.

Moreover, a Rha4N residue has been identified in heteropolymeric O-antigens composed of linear or branched repeating units. The linear tetrasaccharide repeating unit of the O-PS of E. coli O157:H7 [57], an enteric pathogen responsible for outbreaks of hemorrhagic colitis and hemolytic-uremic syndromes, consists of 2-substituted $\alpha$-Rhap 4 NAc, 3-substituted $\alpha$-GalpNAc, 3-substituted $\alpha$-Fucp, and 4-substituted $\beta$-Glcp, and is structurally identical to the O-polysaccharides of Citrobacter sedlakii 6070 and Salmonella enterica O30 (group N) [58], giving also the basis for their serological cross-reactivity [52,59]. The branched O-antigen repeating units that shared a D-perosamine monosaccharide were also revealed in the trisaccharide O-units of Xanthomonas cassavae GSPB 2437 [60] and Pseudomonas stutzeri OX1 [61] and the heptasaccharide repeating unit of the main polysaccharide PS1 of Caulobacter crescentus JS1025 [62].

The chemical diversity of "somatic" O antigens is opposed to the structure of the LPS core region, especially the inner core part, which tends to be conserved within a genus or even family. The fact that the inner LPS core from distantly related bacteria shares structural features reflects the evolutionary relationship and the importance of this region in outer membrane integrity [63]. On the other hand, the outer core shows more structural diversity, as might be expected for a region exposed to the selective pressures of host responses, location of bacteriophage receptors, and environmental stress.

A peculiar characteristic of the core oligosaccharide of the genus Aeromonas is the predominance of heptose residues over hexoses. The complete structure of the core OS of A. hydrophila strain AH-901, which is a rough mutant in a gene encoding mannose transferase, has been elucidated [36]. The core oligosaccharide is composed of four L,D-Hep and two D,D-Hep residues, $\beta$-Glc and $\alpha$-GlcN, as well as one residue of $\alpha$-3-deoxy-D-manno-oct-2-ulosonic acid at the reducing end. Additionally, one of the $\mathrm{D}, \mathrm{D}$-heptoses was non-stoichiometrically substituted with $\beta$-galactopyranose. No charged groups were reported except for a phosphate group at the 4-position of the Kdo. The structure of the LPS core of A. hydrophila strain AH-901 and A. salmonicida subsp. salmonicida (strains A449 and 80204) [36,64] shows great similarities in the inner LPS core and part of the outer LPS core. However, some differences have been found in the distal part of the outer core region (residues: L,D-Hep glycosylating at position C-6 of $\beta$-Glc, D-Gal, and D-GalNAc). Moreover, the structure was further elucidated through identification and characterization of three genomic regions in A. hydrophila AH-3 and A. salmonicida A450 involved in LPS core biosynthesis, which enabled the assignment of LPS core biosynthesis gene function $[39,65]$.

Our latest findings have revealed that the core oligosaccharide with the predominance of heptose residues and the composition $\mathrm{Hep}_{6} \mathrm{Hex}_{1} \mathrm{HexN}_{1} \mathrm{Kdo}_{1} \mathrm{P}_{1}$ represents a structure shared by the LPS core part of strains belonging to the species A. hydrophila and A. bestiarum [28]. On the other hand, we have also reported that the core structure may vary to some extent within Aeromonas bacteria [27].

In this work, the phenol-soluble LPS isolated from A. hydrophila JCM strain 3968 has been structurally characterized. The compositional analysis and MALDI-TOF MS experiments have confirmed that the core oligosaccharide has a structure with the following composition: $\mathrm{Hep}_{6} \mathrm{Hex}_{1} \mathrm{HexN}_{2} \mathrm{Ac}_{1} \mathrm{KdoP}$. Our study shows that the core oligosaccharide structure is slightly different 
from the structure previously reported for A. hydrophila AH-901 and A. salmonicida A450. The presence of both $\mathrm{D}, \mathrm{D}-$ and $\mathrm{L}, \mathrm{D}-\mathrm{Hep}$ isomers makes the core OS studied here most similar to that of A. hydrophila AH-901 [36]. The detection of the 3-substituted GalNAc among permethylated alditol acetates of the dgPS suggests that the O-antigen in the LPS of A. hydrophila JCM 3968 is linked to the GalNAc residue in a manner similar to that in A. salmonicida subsp. salmonicida A450 [39]. In turn, in rough LPS glycoforms, the galactose residue appeared to be a terminal outer core sugar, similarly as has been established for the core of $A$. hydrophila strain AH-901 [36].

For both the LPS core oligosaccharides mentioned [36,39], the distal heptose residue (D,D-Hep or L,D-Hep), which substitutes $\beta$-Glc $p$ at position C-6, is a crucial (outer core) sugar glycosylated at position $\mathrm{C}-4$ by the monosaccharide (galactose or $\mathrm{N}$-acetylgalactosamine) or the disaccharide $\beta$-D-Gal-( $1 \rightarrow 4)-\beta$-D-GalNAc. The latter one, in turn, represents the site of attachment of the O-antigen polysaccharide.

Recently, the studies performed by Merino and Tomas [66] revealed that the structure of the LPS core oligosaccharide from A. salmonicida subsp. pectinolytica (atypical A. salmonicida subspecies) is also consistent with the established core structure of A. hydrophila strain AH-3. Moreover, the genomic analyses of the A. salmonicida subsp. pectinolytica regions engaged in LPS core synthesis showed that the predicted gene functions were in agreement with the chemical structure. Nevertheless, as has been reported, a comparative in silico analysis of region 1 versus the whole sequenced genomes of 121 Aeromonas strains (belonging to the species A. hydrophila, A. veronii, A. caviae, A. media, and Aeromonas spp.) showed some different genes, which will eventually affect the structure of the LPS core oligosaccharide.

The similarity in the LPS core oligosaccharide structure, especially in the inner core part of Aeromonas strains, which corresponds to the similarities in the organization of genomic regions, gives rationale to the recent assumptions [66], i.e., the LPS core genes, especially those structurally non-variable, could complement specific phylogenetic analyses.

In conclusion, the O-PS of A. hydrophila JCM 3968 studied here contains a 4-acetamido-4-deoxy-L-perosamine, a monosaccharide that contributes to the uniqueness of the O-antigen and determines the specificity of serogroup O6. In future, immunochemical studies will be carried out to show structural similarities, but not identity, and serological relatedness of the O-PS of A. hydrophila JCM 3968, serogroup O6, to O-polysaccharides of Aeromonas strains isolated from fish during MAI/MAS outbreaks in Polish aquacultures. It is important to elucidate the serological and structural similarities and differences in O-chain polysaccharides in various serogroups and strains, which contribute to the immunospecificity of Aeromonas.

\section{Materials and Methods}

\subsection{Bacterial Strain, Cultivation Conditions, and Isolation of LPS}

Aeromonas hydrophila reference strain JCM (Japan Collection of Microorganisms) 3968, serogroup O6 was obtained from the collection of the Department of Fish Diseases, National Veterinary Research Institute (Puławy, Poland). The bacterium was cultivated with shaking (120 rpm) on tryptic soy broth (TSB) for $72 \mathrm{~h}$ at $28^{\circ} \mathrm{C}$. The cells were harvested by low speed centrifugation ( $\left.8000 \mathrm{~g}, 20 \mathrm{~min}\right)$. The recovered bacterial cell pellet was washed twice with $0.85 \%$ saline and once more with distilled water.

The bacterial cells ( $5 \mathrm{~g}$ dry mass) were digested with lysozyme, RNAse, and DNAse $(24 \mathrm{~h}, 1 \mathrm{mg} / \mathrm{g})$ and then with Proteinase K ( $36 \mathrm{~h}, 1 \mathrm{mg} / \mathrm{g})$ in $50 \mathrm{mM}$ phosphate buffer ( $\mathrm{pH} 7.0)$ containing $5 \mathrm{mM} \mathrm{MgCl}_{2}$. The suspension was dialyzed against distilled water and freeze-dried. The digested cells were extracted three times with aq $45 \%$ phenol at $68^{\circ} \mathrm{C}$, [35] and the separated layers were dialyzed against tap and distilled water. LPS species recovered from the phenol phase were purified by ultracentrifugation at $105,000 \mathrm{~g}$ and freeze-dried to give a yield of $4.8 \%$ of dry bacterial cell mass. 


\subsection{Degradation of LPS and Isolation of O-polysaccharide}

The phenol-soluble S-LPS (100 mg) was hydrolyzed with aq $2 \%$ acetic acid at $100{ }^{\circ} \mathrm{C}$ for $3 \mathrm{~h}$, and lipid A precipitate was removed by centrifugation. The supernatant was concentrated and then fractionated by GPC on a column $(1.8 \times 80 \mathrm{~cm})$ of Sephadex G-50 fine (Pharmacia, Sweden) using 1\% acetic acid as the eluent and monitoring with a differential refractometer (Knauer, Berlin, Germany). The yield of the O-PS fraction was $31 \%$ of the LPS mass subjected to hydrolysis.

\subsection{Chemical Analyses}

For neutral and amino sugar analysis, the LPS and O-PS samples were hydrolyzed with $2 \mathrm{M}$ $\mathrm{CF}_{3} \mathrm{CO}_{2} \mathrm{H}\left(100{ }^{\circ} \mathrm{C}, 4 \mathrm{~h}\right)$ or $10 \mathrm{M} \mathrm{HCl}$ for $30 \mathrm{~min}$ at $80^{\circ} \mathrm{C}$, respectively, and reduced with $\mathrm{NaBD}_{4}$; this was followed by acetylation with a 1:1 (v/v) mixture of acetic anhydride and pyridine $\left(85^{\circ} \mathrm{C}, 0.5 \mathrm{~h}\right)$.

To release acidic sugar, LPS was dephosphorylated with $48 \%$ aqueous hydrofluoric acid, HF $\left(4{ }^{\circ} \mathrm{C}, 18 \mathrm{~h}\right)$ and dried under vacuum over sodium hydroxide [37]. Methanolysis was performed with $1 \mathrm{M} \mathrm{MeOH} / \mathrm{HCl}\left(85^{\circ} \mathrm{C}, 1 \mathrm{~h}\right)$, and the sample was extracted twice with hexane. The methanol layer was concentrated and the residue was dried and acetylated. The monosaccharides were identified as alditol and aminoalditol acetates [67] as well as acetylated methyl glycosides by GLC-MS on an Agilent Technologies 7890A (Agilent Technologies, Wilmington, DE, USA) gas chromatograph connected to a 5975C MSD (inert XL EI/CI, Agilent Technologies, Wilmington, DE, USA) detector. The chromatograph was equipped with an HP-5MS capillary column (Agilent Technologies, $30 \mathrm{~m} \times 0.25 \mathrm{~mm}$, flow rate of $1 \mathrm{~mL} / \mathrm{min}$, He as carrier gas), and a temperature gradient of $150{ }^{\circ} \mathrm{C}(5 \mathrm{~min})$ to $310^{\circ} \mathrm{C}$ at $5^{\circ} \mathrm{C} \mathrm{min}^{-1}$ was applied. For determination of the absolute configuration [41], the O-PS was subjected to 2-octanolysis $\left(300 \mu \mathrm{L}(S)-(+)-2\right.$-octanol or $(S R)-( \pm)$-2-octanol and $20 \mu \mathrm{L}$ acetyl chloride, $100^{\circ} \mathrm{C}, 3 \mathrm{~h}$ ); the products were acetylated and analyzed by GLC-MS as above. A sample from the polysaccharide of Citrobacter gillenii $\mathrm{O} 9 \mathrm{a}, 9 \mathrm{~b}[40]$ was used as the reference standard of D-Rha4N (D-perosamine).

Methylation of the O-PS $(1.0 \mathrm{mg})$ was carried out with methyl iodide or $\mathrm{CD}_{3}$ iodide in dimethyl sulfoxide in the presence of powdered sodium hydroxide [68]. The products were recovered by extraction with chloroform/water $(1: 1, \mathrm{v} / \mathrm{v})$, hydrolyzed with $10 \mathrm{M} \mathrm{HCl}$ for $30 \mathrm{~min}$ at $80^{\circ} \mathrm{C}, \mathrm{N}$-acetylated, and reduced with $\mathrm{NaBD}_{4}$. The partially methylated alditol acetates derivatives were analyzed by GLC-MS. Methylation of the dgPS $(1.5 \mathrm{mg})$ and the $N$-acetylated core oligosaccharide $(1 \mathrm{mg})$ were carried out with the use of methyl iodide [68]. The products were hydrolyzed with $2 \mathrm{M} \mathrm{CF}_{3} \mathrm{CO}_{2} \mathrm{H}(4 \mathrm{~h}$ at $\left.100^{\circ} \mathrm{C}\right), \mathrm{N}$-acetylated, reduced, acetylated and analyzed by GLC-MS as above.

For fatty acid analysis, a sample of the lipid A (1 mg) was subjected to methanolysis in $2 \mathrm{M}$ methanolic $\mathrm{HCl}\left(85^{\circ} \mathrm{C}, 12 \mathrm{~h}\right)$. The resulting fatty acid methyl esters were extracted with hexane and converted to their $O$-trimethylsilyl (O-TMS) derivatives, as described $[69,70]$. The methanol layer containing methyl glycosides was dried and acetylated with a pyridine-acetic anhydride mixture. The fatty acid derivatives and acetylated methyl glycosides were analyzed by GLC-MS as above.

\subsection{NMR Spectroscopy}

An O-PS sample was deuterium-exchanged by freeze-drying from $\mathrm{D}_{2} \mathrm{O}$ and then examined in $99.98 \% \mathrm{D}_{2} \mathrm{O}$ using acetone as an internal standard $\left(\delta_{\mathrm{H}} 2.225, \delta_{\mathrm{C}} 31.45\right)$. 1D and 2D NMR spectra were recorded at $32{ }^{\circ} \mathrm{C}$ on the $500 \mathrm{MHz}$ NMR Varian Unity Inova instrument (Varian Associates, Palo Alto, CA, USA) using the Varian software Vnmrj V. 4.2 rev. (Agilent Technologies, Santa Clara, CA, USA). The following homonuclear and heteronuclear shift-correlated two-dimensional experiments were conducted for signal assignments and determination of the sugar sequence: ${ }^{1} \mathrm{H},{ }_{1}^{1} \mathrm{H}$ DQF-COSY $,{ }^{1} \mathrm{H},{ }_{1}^{1} \mathrm{H}$ TOCSY, ${ }^{1} \mathrm{H},{ }_{1}^{1} \mathrm{H}$ NOESY, ${ }^{1} \mathrm{H}_{1}{ }^{13} \mathrm{C}$ HSQC, and ${ }^{1} \mathrm{H},{ }^{13} \mathrm{C}$ HMBC. The mixing time was set to 100 and $200 \mathrm{~ms}$ in the TOCSY and NOESY experiments, respectively. The ${ }^{1} \mathrm{H}_{1}{ }^{13} \mathrm{C}$ HSQC experiment with CRISIS based multiplicity editing was optimized for a coupling constant of $146 \mathrm{~Hz}$. The heteronuclear multiple-bond correlation (HMBC) experiment was optimized for $J_{\mathrm{H}, \mathrm{C}}=7$ and $5 \mathrm{~Hz}$, with 2-step low-pass filter 130 and $165 \mathrm{~Hz}$ to suppress one-bond correlations. 


\subsection{MALDI-TOF Mass Spectrometry (MS)}

LPS was analyzed with matrix-assisted laser desorption/ionization time-of flight (MALDI-TOF) mass spectrometry (MS) using a Waters SYNAPT G2-Si HDMS instrument (Waters Corporation, Milford, MA, USA) equipped with a $1 \mathrm{kHz}$ Nd:YAG laser system. Acquisition of the data was performed using MassLynx software version 4.1 SCN916 (Waters Corporation, Wilmslow, United Kingdom). Mass spectra were assigned with a multi-point external calibration using red phosphorous (Sigma-Aldrich, St. Louis, MO, USA) and recorded in the negative ion mode. An LPS sample (at a concentration of $10 \mu \mathrm{g} / \mu \mathrm{L})$ was suspended in a water/methanol $(1: 1, \mathrm{v} / \mathrm{v})$ solution containing $5 \mathrm{mM}$ EDTA and then dissolved by ultrasonication. After desalting with some grains of cation exchange beads (Dowex 50WX8-200; Sigma-Aldrich, St. Louis, MO, USA), one microliter of the sample was transferred onto a well plate covered with a thin matrix film and allowed to dry at room temperature. The matrix solution was prepared from 2', 4',6'-trihydroxyacetophenone (THAP) $(200 \mathrm{mg} / \mathrm{mL}$ in methanol) mixed with nitrocellulose $(15 \mathrm{mg} / \mathrm{mL})$ suspended in 2-propanol/acetone $(1: 1, \mathrm{v} / \mathrm{v})$ in proportion of 4:1 $(\mathrm{v} / \mathrm{v})$, according to the published method [71].

\subsection{SDS-PAGE}

LPS preparations were separated in $12.5 \%$ SDS-Tricine polyacrylamide electrophoresis gel and bands were visualized by silver staining after oxidation with periodate according to the published method [72].

Author Contributions: A.T.S. and K.D. conceived and designed the experiments; A.T.S. and K.D. funding acquisition; K.D., M.K., and A.T.S. performed chemical analyses; K.D. and A.T.S. contributed to interpretation of mass spectra and NMR data; all authors analyzed the data; A.T.S. and K.D. original draft preparation; all authors have reviewed the paper.

Funding: This research was financially supported by the grant from the National Science Centre (Decision No. DEC-2011/03/B/NZ1/01203) and the Polish Ministry of Science and Higher Education research funds (BS-M-11-010-18-2-05 and BS-P-11-010-18-2-04).

Acknowledgments: The authors gratefully thank Andrzej Gamian for the gift of the O-polysaccharide of Citrobacter gillenii O9 (L. Hirszfeld Institute of Immunology and Experimental Therapy, Polish Academy of Sciences, Wrocław, Poland) and Paweł Sowiński for recording the NMR spectra (Intercollegiate NMR Laboratory, Department of Chemistry, Technical University of Gdańsk, Poland). The authors wish to acknowledge the assistance and technical support of MSc Hubert Pietras during LPS isolation and purification.

Conflicts of Interest: The authors declare no conflict of interest.

\section{References}

1. Janda, J.M.; Duffy, P.S. Mesophilic aeromonads in human diseases: Current taxonomy, laboratory infection and infectious diseases spectrum. Rev. Infect. Dis. 1988, 10, 980-997. [CrossRef]

2. Janda, J.M. Recent advances in the study of the taxonomy, pathogenicity and infectious syndromes with the genus Aeromonas. Clin. Microbiol. Rev. 1991, 4, 397-410. [CrossRef]

3. Nawaz, M.; Khan, S.A.; Khan, A.A.; Sung, K.; Tran, Q.; Kerdahi, K.; Steele, R. Detection and characterization of virulence genes and integrons in Aeromonas veronii isolated from catfish. Food Microbiol. 2010, 27, 327-331. [CrossRef]

4. Araujo, R.M.; Arribas, R.M.; Pares, R. Distribution of Aeromonas species in waters with different levels of pollution. J. Appl. Bacteriol. 1991, 71, 182-186. [CrossRef] [PubMed]

5. Janda, J.M.; Abbott, S. The genus Aeromonas: Taxonomy, pathogenicity, and infection. Clin. Microbiol. Rev. 2010, 23, 35-73. [CrossRef]

6. Holmberg, S.D.; Schell, W.L.; Fanning, G.R.; Wachsmuth, I.K.; Blake, P.A.; Brenner, D.J.; Farmer, J.J. Aeromonas intestinal infections in the United States. Ann. Int. Med. 1986, 105, 683-689. [CrossRef]

7. Ali, A.; Carnahan, A.M.; Altwegg, M.; Luthy-Hottenstein, J.; Joseph, S.W. Aeromonas bestiarum sp. nov. (formerly genomospecies DNA group 2 A. hydrophila), a new species isolated from non human sources. Med. Microbiol. Lett. 1996, 5, 156-165. 
8. Kahajanchi, B.K.; Fadl, A.A.; Borchardt, M.A.; Berg, R.L.; Horneman, A.J.; Stemper, M.E.; Joseph, S.W.; Moyer, N.P.; Sha, J.; Chopra, A.K. Distribution of virulence factors and molecular fingerprinting of Aeromonas species isolates from water and clinical samples: Suggestive evidence of water-to-human transmission. Appl. Environ. Microbiol. 2010, 76, 2313-2325. [CrossRef]

9. Figueras, M.J. Clinical relevance of Aeromonas sM503. Rev. Clin. Microbiol. 2005, 16, 145-153. [CrossRef]

10. Tomas, J.M. The Main Aeromonas Pathogenic Factors. ISRN Microbiology. 2012, 22. [CrossRef]

11. Dooley, J.S.G.; Lallier, R.; Shaw, D.H.; Trust, T.J. Electrophoretic and immunochemical analyses of the lipopolysaccharides from various strains of Aeromonas hydrophila. J. Bacteriol. 1985, 164, 263-269. [PubMed]

12. Merino, S.; Rubires, X.; Aguillar, A.; Guillot, J.F.; Tomas, J.M. The role of the O-antigen lipopolysaccharide on the colonization in vivo of the germfree chicken gut by Aeromonas hydrophila serogroup O:34. Microb. Pathog. 1996, 20, 325-333. [CrossRef] [PubMed]

13. Aguilar, A.; Merino, S.; Rubires, X.; Tomas, J. Influence of osmolarity on lipopolysaccharides and virulence of Aeromonas hydrophila serotype O:34 strains grown at $37^{\circ} \mathrm{C}$. Infect. Immun. 1997, 65, 1245-1250.

14. Rabaan, A.A.; Gryllos, I.; Tomas, J.M.; Shaw, J.G. Motility and polar flagellum are required for Aeromonas caviae adherence to HEp-2 cells. Infect. Immun. 2001, 69, 4257-4267. [CrossRef] [PubMed]

15. Garduño, R.A.; Moore, A.R.; Oliver, G.; Lizama, A.L.; Garduño, E.; Kay, W.W. Host cell invasion and intracellular resistance by Aeromonas salmonicida: Role of the S-layer. J. Clin. Microbiol. 2000, 46, 660-668.

16. Asha, A.; Nayak, D.K.; Shankar, K.M.; Mohan, C.V. Antigen expression in biofilm cells of Aeromonas hydrophila employed in oral vaccination of fish. Fish Shellfish Immun. 2004, 16, 429-436. [CrossRef]

17. Caroff, M.; Karibian, D. Structure of bacterial lipopolysaccharides. Carbohydr. Res. 2003, 338, $2431-2447$. [CrossRef]

18. Nazarenko, E.L.; Crawford, R.J.; Iwanowa, E.P. The structural diversity of carbohydrate antigens of selected Gram-negative marine bacteria. Mar. Drugs 2011, 9, 1914-1954. [CrossRef] [PubMed]

19. Sakazaki, R.; Shimada, T. O-Serogrouping for mesophilic Aeromonas strains. Jpn. J. Med. Sci. Biol. 1984, 37, 247-255. [CrossRef] [PubMed]

20. Thomas, L.V.; Gross, R.J.; Cheasty, T.; Rowe, B. Extended serogrouping scheme for motile, mesophilic Aeromonas species. J. Clin. Microbiol. 1990, 28, 980-984.

21. Esteve, C.; Alcaide, E.; Canals, R.; Merino, S.; Blasco, D.; Figueras, M.J.; Tomas, J.M. Pathogenic Aeromonas hydrophila serogroup O:14 and O:81 strains with S-layer. Appl. Environ. Microbiol. 2004, 70, 5898-5904. [CrossRef]

22. Kozinska, A.; Pekala, A. Serotyping of Aeromonas species isolated from Polish fish farms in relation to species and virulence phenotype of the bacteria. Bull. Vet. Inst. Pulawy 2010, 54, 315-320.

23. Show, D.H.; Squires, M.J. O-antigen structure in a virulent strain Aeromonas hydrophila. FEMS Microbiol. Lett. 1984, 24, 277-281. [CrossRef]

24. Merino, S.; Canals, R.; Knirel, Y.A.; Tomas, J.M. Molecular and chemical analysis of the lipopolysaccharide from Aeromonas hydrophila strain AH-1 (Serotype O11). Mar. Drugs 2015, 13, 2233-2249. [CrossRef]

25. Pieretti, G.; Carillo, S.; Lanzetta, R.; Parrilli, M.; Merino, S.; Tomas, J.M.; Corsaro, M.M. Structural determination of the O-specific polysaccharide from Aeromonas hydrophila strain A19 (serogroup O:14) with S-layer. Carbohydr. Res. 2011, 346, 2519-2522. [CrossRef]

26. Knirel, Y.A.; Shashkov, A.S.; Senchenkova, S.N.; Merino, S.; Tomas, J.M. Structure of the O-specific polysaccharide of Aeromonas hydrophila O:34; a case of random O-acetylation of 6-deoxy-L-talose. Carbohydr. Res. 2002, 337, 1381-1386. [CrossRef]

27. Turska-Szewczuk, A.; Duda, K.A.; Schwudke, D.; Pekala, A.; Kozinska, A.; Holst, O. Structural studies of the lipopolysaccharide from the fish pathogen, Aeromonas veronii strain Bs19, serotype O16. Mar. Drugs 2014, 12, 1298-1316. [CrossRef]

28. Turska-Szewczuk, A.; Lindner, B.; Komaniecka, I.; Kozinska, A.; Pekala, A.; Choma, A.; Holst, O. Structural and immunochemical studies of the lipopolysaccharide from the fish pathogen, Aeromonas bestiarum strain K296, serotype O18. Mar. Drugs 2013, 11, 1235-1255. [CrossRef] [PubMed]

29. Wang, Z.; Vinogradov, E.; Larocque, S.; Harrison, B.A.; Li, J.; Altman, E. Structural and serological characterization of the O-chain polysaccharide of Aeromonas salmonicida strains A449, 80204 and 80204-1. Carbohydr. Res. 2005, 340, 693-700. [CrossRef] 
30. Wang, Z.; Liu, X.; Dacanay, A.; Harrison, B.A.; Fast, M.; Colquhoun, D.J.; Lund, V.; Brown, L.L.; Li, J.; Altman, E. Carbohydrate analysis and serological classification of typical and atypical isolates of Aeromonas salmonicida: a rationale for the lipopolysaccharide-based classification of A. salmonicida. Fish Shellfish Immun. 2007, 23, 1095-1106. [CrossRef] [PubMed]

31. Wang, Z.; Liu, X.; Li, J.; Altman, E. Structural characterization of the O-chain polysaccharide of Aeromonas caviae ATCC 15468 lipopolysaccharide. Carbohydr. Res. 2008, 343, 483-488. [CrossRef]

32. Turska-Szewczuk, A.; Pietras, H.; Duda, K.A.; Kozińska, A.; Pękala, A.; Holst, O. Structure of the O-specific polysaccharide from the lipopolysaccharide of Aeromonas sobria strain Pt312. Carbohydr. Res. 2015, 403, 142-148. [CrossRef]

33. Turska-Szewczuk, A.; Kozinska, A.; Russa, R.; Holst, O. The structure of the O-specific polysaccharide from the lipopolysaccharide of Aeromonas bestiarum strain 207. Carbohydr. Res. 2010, 345, 680-684. [CrossRef]

34. Turska-Szewczuk, A.; Guz, L.; Lindner, B.; Pietras, H.; Russa, R.; Holst, O. Structural characterization of the $\mathrm{O}$-specific polysaccharide from the lipopolysaccharide of fish pathogen Aeromonas bestiarum strain P1S. Carbohydr. Res. 2011, 346, 815-821. [CrossRef]

35. Westphal, O.; Jann, K. Bacterial lipopolysaccharide. Extraction with phenol-water and further applications of the procedure. Meth. Carbohydr. Chem. 1965, 5, 83-91.

36. Knirel, Y.A.; Vinogradov, E.; Jimenez, N.; Merino, S.; Tomas, J.M. Structural studies on the R-type lipopolysaccharide of Aeromonas hydrophila. Carbohydr. Res. 2004, 339, 787-793. [CrossRef]

37. Pieretti, G.; Corsaro, M.M.; Lanzetta, R.; Parrilli, M.; Nicolaus, B.; Gambacorta, A.; Lindner, B.; Holst, O. Structural characterization of the core region of the lipopolysaccharide from the haloalkaliphilic Halomonas pantelleriensis: identification of the biological O-antigen repeating unit. Eur. J. Org. Chem. 2008, 721-728. [CrossRef]

38. Domon, B.; Costello, C.E. A systamatic nomenclature for carbohydrate fragmentations in FAB MS/MS spectra of glycoconjugates. Glycoconj. J. 1988, 5, 397-409. [CrossRef]

39. Jimenez, N.; Lacasta, A.; Vilches, S.; Reyes, M.; Vazquez, J.; Aquillini, E.; Merino, S.; Regue, M.; Tomas, J.M. Genetics and proteomics of Aeromonas salmonicida lipopolysaccharide core biosynthesis. J. Bacteriol. 2009, 191, 2228-2236. [CrossRef]

40. Lipiński, T.; Zatonsky, G.V.; Kocharova, N.A.; Jaquinod, M.; Forest, E.; Shashkov, A.S.; Gamian, A.; Knirel, Y.A. Structures of two O-chain polysaccharides of Citrobacter gillenii O9a, 9b lipopolysaccharide. A new homopolymer of 4-amino-4,6-dideoxy-D-mannose (perosamine). Eur. J. Biochem. 2002, 269, 93-99. [CrossRef]

41. Leontein, K.; Lindberg, B.; Lönngren, J. Assignment of absolute configuration of sugars by GLC of their acetylated glycosides formed from chiral alcohols. Carbohydr. Res. 1978, 62, 359-362. [CrossRef]

42. Lipkind, G.M.; Shashkov, A.S.; Knirel, Y.A.; Vinogradov, E.V.; Kochetkov, N.K. A computer-assisted structural analysis of regular polysaccharides on the basis of 13C-n.m.r. data. Carbohydr. Res. 1988, 175, 59-75. [CrossRef]

43. Ovchinnikova, O.G.; Kocharova, N.A.; Katzenellenbogen, E.; Zatonsky, G.V.; Shashkov, A.S.; Knirel, Y.A.; Lipiński, T.; Gamian, A. Structures of two O-polysaccharides of the lipopolysaccharide of Citrobacter youngae PCM 1538 (serogroup O9). Carbohydr. Res. 2004, 339, 881-884. [CrossRef]

44. Jansson, P.E.; Kenne, L.; Widmalm, G. Computer-assisted structural analysis of polysaccharides with an extended version of CASPER using ${ }^{1} \mathrm{H}$ - and ${ }^{13} \mathrm{C}-\mathrm{NMR}$ data. Carbohydr. Res. 1989, 188, 169-191. [CrossRef]

45. Shashkov, A.S.; Lipkind, G.M.; Knirel, Y.A.; Kochetkov, N.K. Stereochemical factors determining the effects of glycosylation on the ${ }^{13} \mathrm{C}$ NMR shifts in carbohydrates. Magn. Reson. Chem. 1988, 26, 735-747. [CrossRef]

46. Mogensen, T.H. Pathogen recognition and inflammatory signaling in innate immune defenses. Clin. Microbiol. Rev. 2009, 22, 240-273. [CrossRef]

47. Kaszowska, M.; Wojcik, M.; Sudnienko, J.; Lugowski, C.; Lukasiewicz, J. Structure-activity relationship of Plesiomonas shigelloides lipid A to the production of TNF- $\alpha$, IL-1 $\beta$, and IL-6 by human and murine macrophages. Front. Immunol. 2017, 8, 1741. [CrossRef]

48. Karaś, M.A.; Turska-Szewczuk, A.; Janczarek, M.; Szuster-Ciesielska, A. Glycoconjugates of Gram-negative bacteria and parasitic protozoa - are they similar in orchestrating the innate immune response? Innate Immun. 2019, 25, 73-96. [CrossRef] [PubMed] 
49. Arteaga Garibay, R.I.; Aguilera-Arreola, M.G.; Navarro Ocana, A.; Giono Cerezo, S.; Sanchez Mendoza, M.; Molina Lopez, J.; Eslava Campos, C.; Cravioto, A.; Castro-Escarpulli, G. Serogroups, K1 antigen, and antimicrobial resistance patterns of Aeromonas spp. strains isolated from different sources in Mexico. Mem. Inst. Oswaldo Cruz 2006, 101, 157-161. [CrossRef]

50. Bundle, D.R.; Cherwonogrodzky, J.W.; Perry, M.B. The structure of the lipopolysaccharide O-chain (M antigen) and polysaccharide B produced by Brucella melitensis 16M. FEBS Lett. 1987, 216, 261-264. [CrossRef]

51. Kubler-Kielb, J.; Vinogradov, E. Reinvestigation of the structure of Brucella O-antigens. Carbohydr. Res. 2013, 378, 144-147. [CrossRef] [PubMed]

52. Knirel, Y.A.; Kocharova, N.A.; Bystrova, O.V.; Katzenellenbogen, E.; Gamian, A. Structures and serology of the O-specific polysaccharides of bacteria of the genus Citrobacter. Arch. Immunol. Ther. Exp. 2002, 50, 379-391.

53. Caroff, M.; Bundle, D.R.; Perry, M.B.; Cherwonogrodzky, J.W.; Dunkan, J.R. Antigenic S-type lipopolysaccharide of Brucella abortus 1119-3. Infect. Immun. 1984, 46, 384-388.

54. Caroff, M.; Bundle, D.R.; Perry, M.B. Structure of the O-chain of the phenol-phase soluble cellular lipopolysaccharide of Yersinia enterocolitica serotype O:9. Eur. J. Biochem. 1984, 139, 195-200. [CrossRef]

55. Kenne, L.; Lindberg, B.; Unger, P.; Gustafsson, B.; Holme, T. Structural studies of the Vibrio cholerae O-antigen. Carbohydr. Res. 1982, 100, 341-349. [CrossRef]

56. Haishima, Y.; Kondo, S.; Hisatsune, K. The occurrence of $\alpha(1 \rightarrow 2)$ linked $N$-acetylperosamine-homopolymer in lipopolysaccharides of non-O1 Vibrio cholerae possessing an antigenic factor in common with O1 V. cholerae. Microbiol. Immunol. 1990, 34, 1049-1054. [CrossRef] [PubMed]

57. Perry, M.B.; MacLean, L.; Griffith, D.W. Structure of the O-chain polysaccharide of the phenol-phase soluble lipopolysaccharide of Escherichia coli O:157:H7. Biochem. Cell Biol. 1986, 64, 21-28. [CrossRef] [PubMed]

58. Bundle, D.R.; Gerken, M.; Perry, M.B. Two-dimensional nuclear magnetic resonance at $500 \mathrm{MHz:}$ the structural elucidation of a Salmonella serogroup N polysaccharide antigen. Can. J. Chem. 1986, 64, 255-264. [CrossRef]

59. Vinogradov, E.; Conlan, J.W.; Perry, M.B. Serological cross-reaction between the lipopolysaccharide O-polysaccharide antigens of Escherichia coli O157:H7 and strains of Citrobacter freundii and Citrobacter sedlakii. FEMS Microbiol. Lett. 1998, 190, 157-161. [CrossRef]

60. Senchenkova, S.N.; Shashkov, A.S.; Knirel, Y.A.; Wydra, K.; Witt, F.; Mavridis, A.; Rudolph, K. Structure of two O-polysaccharide of Xanthomonas cassavae GSPB 2437. Carbohydr. Res. 2004, 339, 157-160. [CrossRef]

61. Leone, S.; Izzo, V.; Lanzetta, R.; Molinaro, A.; Parrilli, M.; Di Donato, A. The structure of the O-polysaccharide from Pseudomonas stutzeri OX1 containing two different 4-acylamido-4,6-dideoxy-residues, tomosamine and perosamine. Carbohydr. Res. 2005, 340, 651-656. [CrossRef] [PubMed]

62. Jones, M.D.; Vinogradov, E.; Nomellini, J.F.; Smit, J. The core and O-polysaccharide structure of the Caulobacter crescentus lipopolysaccharide. Carbohydr. Res. 2015, 402, 111-117. [CrossRef]

63. Raetz, C.R.H.; Whitfield, C. Lipopolysaccharide endotoxins. Annu. Rev. Biochem. 2002, 71, 635-700. [CrossRef]

64. Wang, Z.; Li, J.; Vinogradov, E.; Altman, E. Structural studies of the core region of Aeromonas salmonicida subsp. salmonicida lipopolysaccharide. Carbohydr. Res. 2006, 341, 109-117. [CrossRef]

65. Jimenez, N.; Canals, R.; Lacasta, A.; Kondakova, A.; Lindner, B.; Knirel, Y.A.; Merino, S.; Regue, M.; Tomas, J.M. Molecular analysis of three Aeromonas hydrophila AH-3 (Serotype O34) lipopolysaccharide core biosynthesis gene clusters. J. Bacteriol. 2008, 190, 3176-3184. [CrossRef]

66. Merino, S.; Tomas, J.M. The Aeromonas salmonicida lipopolysaccharide core from different subspecies: the unusual subsp. pectinolytica. Front. Microbiol. 2016, 7, 125. [CrossRef]

67. Russa, R.; Urbanik-Sypniewska, T.; Lindström, K.; Mayer, H. Chemical characterization of two lipopolysaccharide species isolated from Rhizobium loti NZP2213. Arch. Microbiol. 1995, 163, 345-351. [CrossRef] [PubMed]

68. Ciucanu, I.; Kerek, F. A simple and rapid method for the permethylation of carbohydrates. Carbohydr. Res. 1984, 131, 209-217. [CrossRef]

69. Komaniecka, I.; Choma, A.; Lindner, B.; Holst, O. The structure of a novel lipid A from the lipopolysaccharide of Bradyrhizobium elkanii containing three mannose units in the backbone. Chem. Eur. J. 2010, 16, 2922-2929. [CrossRef] 
70. Pieretti, G.; Corsaro, M.M.; Lanzetta, R.; Parrilli, M.; Vilches, S.; Merino, S.; Tomas, J.M. Structure of the core region from the lipopolysaccharide of Plesiomonas shigelloides strain 302-73 (serotype O1). Eur. J. Org. Chem. 2009, 2009, 1365-1371. [CrossRef]

71. Silipo, A.; Molinaro, A.; Sturiale, L.; Dow, J.M.; Erbs, G.; Lanzetta, R.; Newman, M.A.; Parrilli, M. The elicitation of plant innate immunity by lipooligosaccharide of Xanthomonas campestris. J. Biol. Chem. 2005, 280, 33660-33668. [CrossRef] [PubMed]

72. Tsai, C.M.; Frasch, C.E. A sensitive silver stain for detecting lipopolysaccharides in polyacrylamide gels. Anal. Biochem. 1982, 119, 115-119. [CrossRef]

(C) 2019 by the authors. Licensee MDPI, Basel, Switzerland. This article is an open access article distributed under the terms and conditions of the Creative Commons Attribution (CC BY) license (http://creativecommons.org/licenses/by/4.0/). 